\title{
Transformation of Shen Kong Borderlands
}

\author{
Mary Ann O'DONNELL \\ Jonathan BACH \\ Denise Y. HO
}

I $n$ August 1980, the Shenzhen Special Economic Zone (SEZ) was formally established, along with SEZs in Zhuhai, Shantou, and Xiamen. China's fifth SEZ, Hainan Island, was designated in 1988. Yet, in 2020, the only $S E Z$ to receive national attention on its fortieth anniversary was Shenzhen. Indeed, General Secretary Xi Jinping attended the celebration, reminding the city, the country, and the world not only of Shenzhen's pioneering contributions to building Socialism with Chinese Characteristics, but also that the 'construction of the Guangdong-Hong Kong-Macau Greater Bay Area is a major national development strategy, and Shenzhen is an important engine for the construction of the Greater Bay Area' (Xi 2020). Against this larger background, many interpreted the General Secretary's celebration of Shenzhen as putting Hong Kong in its place, so to speak; Hong Kong may have contributed to the SEZ's development, but the region's future is being shaped in and through Shenzhen.

This forum offers historical and ethnographic accounts of the Shenzhen-Hong Kong borderlands as sites where cross-border policies, situations, and aspirations continue to inform and transform everyday life. In political documents, newspaper articles, and the names of businesses, Shenzhen-Hong Kong is shortened to 'Shen Kong' (深港), suturing the cities together as specific, yet diverse, sociotechnical formations built on complex legacies of colonial occupation and Cold War flare-ups, checkpoints and boundaries, quasi-legal business opportunities, and cross-border peregrinations. The following essays show how, set against its changing cultural meanings and sifting of social orders, the border is continuously redeployed and exported as a mobile imaginary while it is experienced as an everyday materiality. Taken together, the articles compel us to consider how borders and border protocols have been critical to Shenzhen's success over the past four decades. Indeed, we would argue, Shenzhen succeeds to the extent that it remains a liminal space of passage and transformation. As the Greater Bay Area once again remakes the region's cultural geography, the stories and voices herein provide food for speculative thought about today's Pearl River Delta, between and within China's domestic and international borders. -
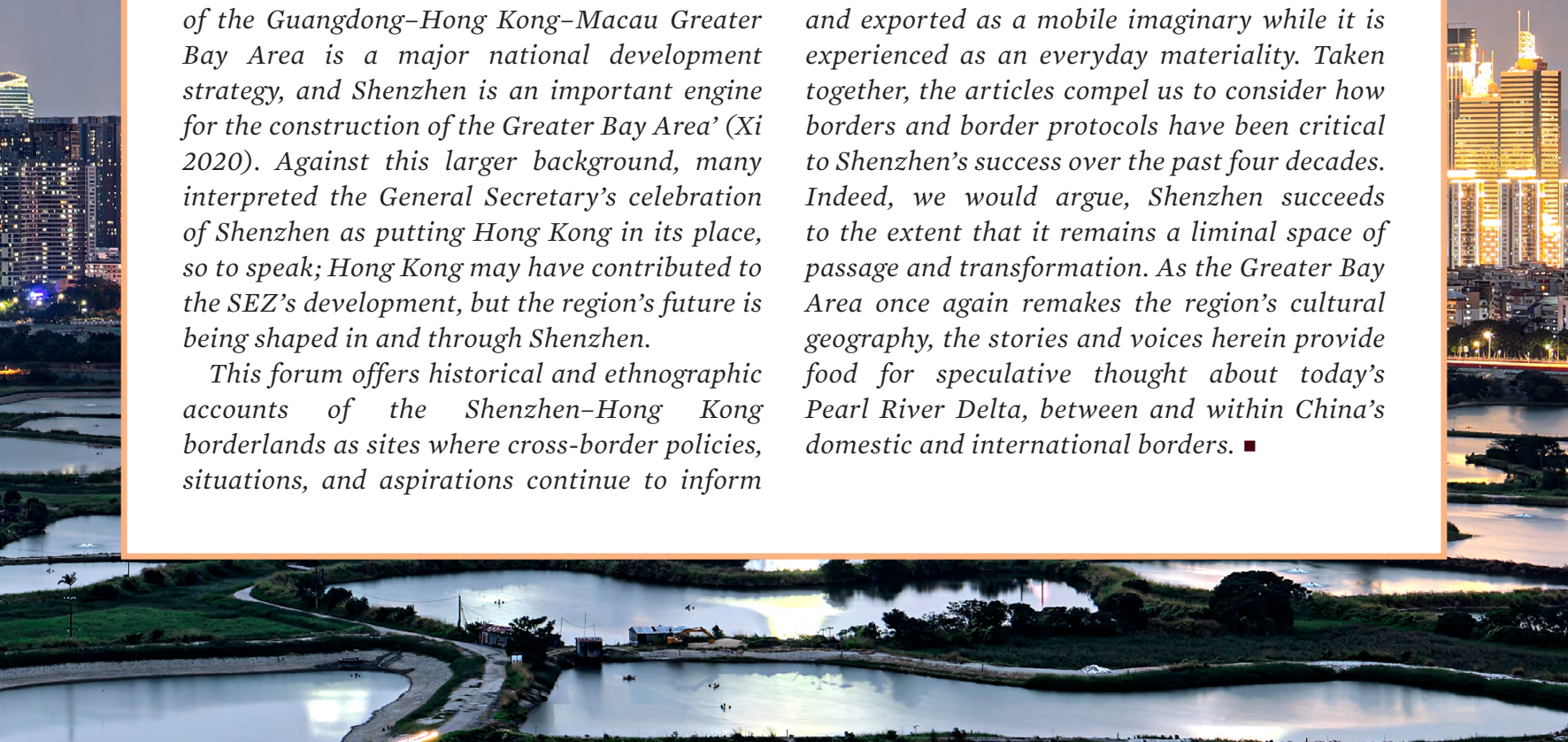
This text is taken from Made in China Journal: Volume 5, Issue 3, 2020, edited by Ivan Franceschini and Nicholas Loubere, published 2021 by ANU Press, The Australian National University, Canberra, Australia.

doi.org/10.22459/MIC.05.03.2020.12 